\title{
KAJIAN PRAKTIS PENILAIAN \\ BENDA CAGAR BUDAYA LOGAM (DALAM PENENTUAN IMBALAN JASA) ${ }^{2}$
}

\author{
Edi Triharyantoro \\ (Balai Pelestarian Peninggalan Purbakala Samarinda \\ Wilayah Kerja Kalimantan)
}

\begin{abstract}
ABSTRAK
Penilaian terhadap cagar budaya berbahan logam dalam proses pemberian imbalan jasa seringkali menjadi masalah, karena tidak ada rujukan yang jelas. Kebijakan yang diambil pemerintah berbeda-beda dalam berbagai kasus, sehingga memunculkan rasa ketidakadilan di masyarakat. Untuk memecahkan masalah tersebut kiranya perlu ada rujukan cara penilaian yang lebih baku. Dalam makalah ini diajukan setidaknya ada tiga unsur yang dapat membantu proses identifikasi dan interpretasi artefak logam, yaitu konteks, kelangkaan dan umur. Ketiganya merupakan pertimbangan dari 'dalam' (intrinsic). Selain itu, ada pula unsur untuk pertimbangan dari 'luar', yaitu harga standar logam dan harga kolektor. Perpaduan pertimbangan atau alasan tersebut akan sangat membantu membakukan nilai atau harga dalam proses pemberian imbalan jasa.
\end{abstract}

Kata-kata kunci: arkeologi, logam, temuan

\section{SOME CONSIDERATIONS IN VALUE ASSESSMENT OF METAL ARTIFACTS FOR COMPENSATION}

\begin{abstract}
Value assesment of metal artifacts for compensation is problematic in heritage management. In Indonesia, there is no guideline to value a metal artifact and archaeological offices use different standard to determine the value metal artifacts. This has been seen as unjust among the society. In this paper, three essential aspects are proposed to be used in interpreting and identifying metal artifacts for compensation: context, rarity, and age. These three aspects are "inner considerations". Along side with those aspects, we need to also consider other two "outer considerations", i.e. present standard price for metal and collector's price. Combining those inner and outer considerations will help greatly to determine the value of metal artifacts for compensation.
\end{abstract}

Key words: Archaeological heritage, metal, rewards, found, assesment

2 Pernah disampaikan pada Sarasehan Penilaian BCB di LPP Convention Hotel yang diselenggarakan oleh BP 3 Jawa Tengah, Yogyakarta, 25 - 27 November 2008

Berkala Arkeologi Tafun XXX Edisi $\mathcal{N}$. 2 / November 2010 


\section{PENDAHULUAN}

Penilaian terhadap benda cagar budaya (temuan, hibah, dan sebagainya) adalah merupakan persyaratan hukum yang harus dilakukan dalam konteks perlindungan dan pelestariannya. Secara prosedural, kegiatan penilaian itu dilakukan setelah benda tersebut diteliti dan dinyatakan oleh tim ahli sebagai benda cagar budaya yang mempunyai nilai sejarah, ilmu pengetahuan dan kebudayaan sehingga dilindungi oleh Undang - undang No. 5 Tahun 1992 Tentang Benda Cagar Budaya.

Penilaian yang dimaksudkan dalam tulisan ini terutama adalah untuk menentukan tafsiran harga nominal benda cagar budaya tersebut, khususnya benda cagar budaya yang dibuat dari logam. Diakui bahwa selama ini pelaksanaan penilaian untuk menentukan tafsiran harga nominal benda cagar budaya yang akan diberikan sebagai imbalan jasa / ganti untung, belum didukung oleh petunjuk teknis atau petunjuk pelaksanaan yang jelas sebagai landasan pelaksanaannya. Oleh karena itu, hasilnya adalah tafsiran yang berbeda-beda karena mengikuti kewenangan masing masing instansi, baik itu di tingkat Direktorat maupun BP 3 .

Tidak adanya dasar atau acuan aturan dalam penilaian tersebut, akan membawa dampak psikologi bagi masyarakat yang menemukan dan menyerahkannya kepada instansi yang menangani benda cagar budaya, karena hal ini terkait dengan keuntungan masyarakat seperti yang dinyatakan oleh Mac Manamon (1997) yang dikutip oleh George S. Sainth dan John E. Ehrenhard dalam artikelnya "Protecting the Past to Benefit the Public". Disebutkan, ketika berbicara tentang "public benefit", sebenarnya yang dihadapi bukan sekedar satu masyarakat, tetapi umat manusia secara umum. Oleh karena itu, kita berhadapan dengan orang - orang yang sangat bervariasi tingkat pemahaman mereka (Sainth dan Ehrenhard, 2002: 123). Selain daripada itu, tidak adanya standarisasi harga dalam imbalan jasa tersebut menunjukkan lemahnya akuntabilitas kinerja lembaga itu sendiri.

\section{Dasar Hukum}

Pijakan hukum dari tema makalah ini ada dalam beberapa pasal dari Peraturan Pemerintah Republik Indonesia No. 10 Tahun 1993 Tentang Pelaksanaan Undang - undang Nomor 5 Tahun 1992 tentang Benda Cagar Budaya, khususnya pasal 13 ayat (1), (4), pasal 15 (1) serta pasal $8(5)$.

Pasal 13 (1), setiap orang yang menemukan atau mengetahui ditemukannya benda cagar budaya, benda yang diduga benda cagar budaya, benda berharga yang tidak diketahui pemiliknya, atau situs wajib melaporkannya kepada instansi yang bertanggungjawab atas perlindungan benda cagar budaya seperti Kepolisian Negara Republik Indonesia atau aparat pemerintah daerah, dalam jangka waktu selambat - lambatnya 14 hari sejak penemuan tersebut.

Pasal $13(4)$, untuk menentukan temuan tersebut sebagai benda cagar budaya atau situs, dilakukan penelitian. 
Pasal 15 (1), apabila hasil penelitian menunjukkan benda temuan tersebut sebagai benda cagar budaya sebagaimana yang dimaksud dalam pasal 3 (1), benda cagar budaya tersebut dimiliki oleh Negara dan kepada penemu dapat diberikan imbalan.

\section{KAJIAN NILAI PENTING}

Dalam proses imbal jasa benda cagar budaya (logam) salah satu tahap yang paling penting dilakukan adalah penentuan nilai penting dari benda cagar budaya tersebut. Tahap penentuan nilai penting itu menjadi sangat strategis karena hasilnya akan menjadi dasar untuk menentukan langkah - langkah pengelolaannya. Bahkan apabila tidak ada penentuan nilai penting, sebenarnya tidak mungkin ditentukan tindakan pelestariannya, karena pada hakekatnya tujuan pelestarian itu adalah mempertahankan nilai penting benda cagar budaya agar tidak hilang ataupun berkurang (Pearson dan Sullivan, 1995; Mc Gimsey, 1977; Tanudirjo, 2004).

Namun, dalam kenyataanya harus diakui bahwa tahap penentuan nilai penting ini justru merupakan bagian yang paling sulit, masalahnya tidak ada patokan yang jelas untuk mengukur nilai penting suatu benda cagar budaya (Tanudirjo, ibid). Bagi kita nilai penting tersebut pada hakekatnya sudah terlihat dalam Undang - undang No. 5 Tahun 1992 Tentang Banda Cagar Budaya, khususnya pasal (1) dinyatakan bahwa banda cagar budaya adalah benda buatan manusia, benda alam, dan situs yang berumur atau memiliki masa gaya sekurang - kurangnya 50 tahun serta dianggap mempunyai nilai penting bagi sejarah, ilmu pengetahuan dan kebudayaan. Namun, diakui bahwa nilai penting tersebut sangatlah luas penjabarannya, sehingga banyak para ahli yang mencoba membuat perumusannya. Scovill menyatakan bahwa nilai penting bagi bidang sejarah dapat diukur dari kemampuan sumber daya arkeologi untuk menjadi bukti yang berbobot dari kehidupan pada masa prasejarah, sejarah, atau peristiwa tertentu yang bersejarah, termasuk sejarah ilmu pengetahuan (Scovill, 1977). Sedang sumber daya arkeologi mempunyai nilai penting bagi pengetahuan jika mempunyai potensi untuk diteliti lebih lanjut dalam menjawab masalah masalah dalam bidang keilmuan (Schiffer dan Gumerman, 1977). Adapun Person dan Sullivan (1995) merinci nilai penting bagi kebudayaan ke dalam 5 unsur utama yaitu nilai penting secara estetis, arsitektural, sejarah, ilmu pengetahuan, dan sosial. Mengutip Burra Charter, mereka menyatakan bahwa nilai estetis muncul dari pancaindera manusia (sensory), sehingga penilaiannya mempertimbangkan keserasian hubungan antara bentuk, ukuran(scale), warna, tekstur, bahan, bau, dan suara dengan lokasi dan pemanfaatannya. Apabila nilai estetis ini masuk dalam konteks saujana (landscape) dapat pula dinilai kemampuannya untuk menyajikan pemandangan yang mengesankan (scenic or visual quality), untuk membangkitkan perasaan khusus bagi masyarakat, untuk memberikan makna (meaning) tertentu bagi masyarakat, misalnya untuk menumbuhkan 
rasa keterikatan dengan tempat tersebut, dan merupakan paduan serasi antara alam dan budaya manusia.

Dari beberapa konsep yang telah telah diajukan para ahli tersebut, maka untuk menentukan nilai penting benda cagar budaya logam dalam proses pemberian imbalan, perlu kiranya diberi variabel - variabel pembobotan. Menurut hemat penulis, ada 3 pembobotan yang mendukung nilai penting tersebut dan dapat dipertimbangkan dalam penentuan imbalan.

\section{A. Kontekstual}

Robert J. Sharer dan Ashmore memberi contoh ekstrim tentang makna kontekstual dalam pengertian arkeologi. Perbedaan tujuan antara arkeolog dan pencari harta karun adalah bahwa pencari harta karun tidak akan bersusah payah mencatat asal atau konteks 2 bejana temuannya, karena perhatiannya hanya pada uang dari hasil penjualan temuannya. Sementara itu arkeolog akan memahami bahwa 2 bejana tersebut ditemukan dalam asosiasi di lantai sebuah makam. Mereka menduga bahwa 2 bejana tersebut memang disimpan dalam waktu yang sama dan ditinggalkan tidak tersentuh sampai mereka ditemukan. Bejana yang tidak diketahui itu kemudian ditentukan dengan pertanggalan yang sama (Sharer dan Ashmore: 1993).

Dalam hal yang sama Colin Renfrew dan Paul Bahn menyebutkan bahwa untuk merekonstruksi aktivitas manusia masa lampau pada suatu situs, adalah sangat penting memahami konteks dari temuan, termasuk artefak, fitur struktur, atau sisa - sisa organik. konteks temuan terdiri atas matriks-nya (material yang mengelilinginya, pada umumnya beberapa jenis sedimen seperti kerikil, pasir atau tanah liat), tempat asalnya (horizontal atau vertikal terhadap matrix), dan hubungannya dengan temuan - temuan lain. Pada abad ke-19, misalnya, pernah ditemukan peralatan batu berhubungan dengan tulang - tulang binatang yang sudah punah, sehingga dapat diinterpretasikan keterkaitan antara alat dan kepunahan hewan. Arkeolog meyakini pentingnya mengenali dan membuat laporan akurat tentang konteks antar tinggalan - tinggalan arkeologi, karena menyadari benar tragedi yang diakibatkan ketika pencari harta karun menggali situs secara membabi buta mencari kekayaan, tanpa pencatatan matrix, asal, dan hubungan. Seluruh informasi kontekstual musnah. Vas bunga mungkin obyek sangat menarik bagi seorang kolektor, tetapi bagi arkeolog akan jauh lebih bernilai informasi tentang masyarakat yang memproduksinya atau fungsi vas tersebut, sehingga ia akan berusaha mencatat secara rinci tempat vas itu ditemukan (di makam, parit, atau rumah), serta hubungannya dengan artefak lain (senjata, peralatan atau tulang binatang) (Renfrew dan Bahn: 1993: $42-43$ ). 


\section{B. Potensi Kelangkaan}

Bagi semua bangsa, mereka seolah memiliki rasa kewajiban intrinsik untuk memberi makna yang tinggi terhadap benda cagar budaya, karena secara tidak langsung benda cagar budaya sangat berkaitan dengan eksistensi suatu bangsa. Pandangan masyarakat bangsa terhadap Benda Cagar Budaya tersebut muncul karena potensi yang dikandung oleh Benda Cagar Budaya itu sendiri.

Kata "potensi" itu sendiri, menurut kamus Bahasa Indonesia Kontemporer, berarti kemampuan, kekuatan atau daya yang dapat dikembangkan. Berpotensi artinya mempunyai potensi, sebagai contoh daerah itu mempunyai potensi menjadi obyek wisata (Salim, 1999: 1184).

Potensi benda cagar budaya tersirat di dalam makna yang dapat diberikan benda cagar budaya itu. menurut pasal I ayat (1) Undang undang RI. No. 5 Tahun 1992 Tentang Benda Cagar Budaya, yang dimaksud dengan Benda Cagar Budaya adalah :

a. Benda buatan manusia bergerak atau tidak bergerak, yang berupa kesatuan atau kelompok, atau bagian - bagiannya atau sisa - sisanya yang berumur sekurang - kurangnya 50 tahun, atau mewakili masa gaya yang khas dan mewakili masa gaya sekurang - kurangnya 50 (lima puluh) tahun, serta dianggap mempunyai nilai penting bagi sejarah, ilmu pengetahuan dan kebudayaan;

b. Benda alam yang dianggap mempunyai nilai penting bagi sejarah, ilmu pengetahuan dan kebudayaan.

Dari rumusan Benda Cagar Budaya $(B C B)$ tersebut sebenarnya terselip potensi - potensi di dalamnya. Sebagai contoh, kriteria harus mewakili gaya yang khas dan masa gaya sekurang - kurangnya 50 (lima puluh) tahun. Kriteria ini secara eksplisit mengisyaratkan adanya potensi "kelangkaan" dari BCB itu sendiri, sebab konotasi khas berarti tidak akan dijumpai di tempat lain. Dengan demikian, kriteria kelangkaan benda cagar budaya itu dapat berupa: ide - ide kesenian (misal, tentang motif hias), bahan, dan organisasi ruang (monumen). Ide - ide kesenian meskipun sifatnya universal (umum) namun sifat khas masyarakat pendukungnya tidak bisa dikelabuhi, misalnya hiasan stiliran hasil kesenian masyarakat Islam di Mantingan, Jepara, Jawa Tengah. Begitu pula dengan bahan, sifat spektakuler "gigantex" dalam pembuatan bangunan candi di Kamboja menggunakan batu besar yang beratnya mencapai 1,2 ton adalah salah satu contoh kekhasan bahan. Demikian pula, organisasi ruang (monumen) pada, peninggalan prasejarah Stonehenge di Inggris bisa dijadikan contoh (Triharyantoro, 2000: 31).

Kekhasan gaya adalah potensi lain yang ada dalam benda cagar budaya. Kusen memadankan kata "gaya" dengan kata "style" dalam bahasa Inggris Kata style memiliki arti: (1) ragam ungkapan; (2) ragam ungkapan yang bersifat khas dari suatu bangsa, periode, perorangan atau aliran; (3) ragam tertentu atau bersifat khas dari penyajian, penyusunan atau pertunjukan dalam suatu seni, pekerjaan atau hasil produksi, terutama 
dalam cabang - cabang seni adiluhung atau Fine arts (Webster's New Internasional Dictionary: 225; Kusen: 1995: 14).

Edmund Burke Feldman membuat ulasan tentang style atau gaya sebagai berikut. Konsep tentang gaya tidak dapat dipisahkan dari studi tentang seni meskipun sesungguhnya hal itu dapat menjadi ketidakjelasan karena istilah tersebut memiliki banyak arti yang berbeda. Kadang - kadang gaya menunjukkan kepada karya dari masa atau periode sejarah tertentu, atau menunjuk kepada karya seni suatu bangsa atau beberapa bangsa, atau karya seni dari suatu wilayah dalam sebuah Negara (1 Bidang). Sedangkan menurut Edi Sedyawati dengan mengutip Balasubrahmanyam memberi batasan gaya seni adalah (Sedyawati, 1985: 38) "Gaya seni adalah segala keleluasaan kenampakan dan struktur dalam suatu karya arsitektur, seni arca atau seni lukis, yang dengan alasan dan cara penciptaannya, membuatnya khas tak dapat tidak bagi suatu masa dalam sejarah".

Dari uraian di atas menjadi jelas bahwa gaya yang khas dari benda cagar budaya pada hakekatnya adalah cerminan potensi "kelangkaan" yang dimiliki oleh BCB itu sendiri. Sebab, meskipun secara universal karya seni masing - masing bangsa mempunyai unsur - unsur keminipan, namun ekspresi keindahan seniman pendukungnya berbeda - beda secara khas sehingga menciptakan kelangkaan masing - masing. Dengan demikian, potensi kelangkaan $\mathrm{BCB}$ pada dasarnya patut juga digunakan sebagai salah satu kriteria penting dalam pertimbangan manajemen tinggalan arkeologi (Hunter dan Ralston, 1993: 188).

\section{Umur}

Waktu atau umur artefak merupakan hal yang sangat esensial dalam kajian arkeologi. Karena di dalam umur ada kontinuitas yang mengandung pergantian peristiwa - peristiwa. Kita pahami bahwa peristiwa adalah ciri atau tanda dari perubahan. Oleh karena itu, perubahan adalah tanda kronologis dalam arkeologi (Michels: 1973: 9).

Demikian penting umur sebagai penghimpun waktu maka, akan diutamakan dalam perspektif ke masa depan. Dengan demikian, umur benda cagar budaya yang mengandung nilai - nilai akan sangat berpengaruh dalam kehidupan di masa kini. Sebab masa kini tidak menjadi lampau, tetapi sebaliknya yang lampau menjadi sekarang, karena sekarang itu merupakan perkembangan dari yang lampau (Meulen, 1987). 

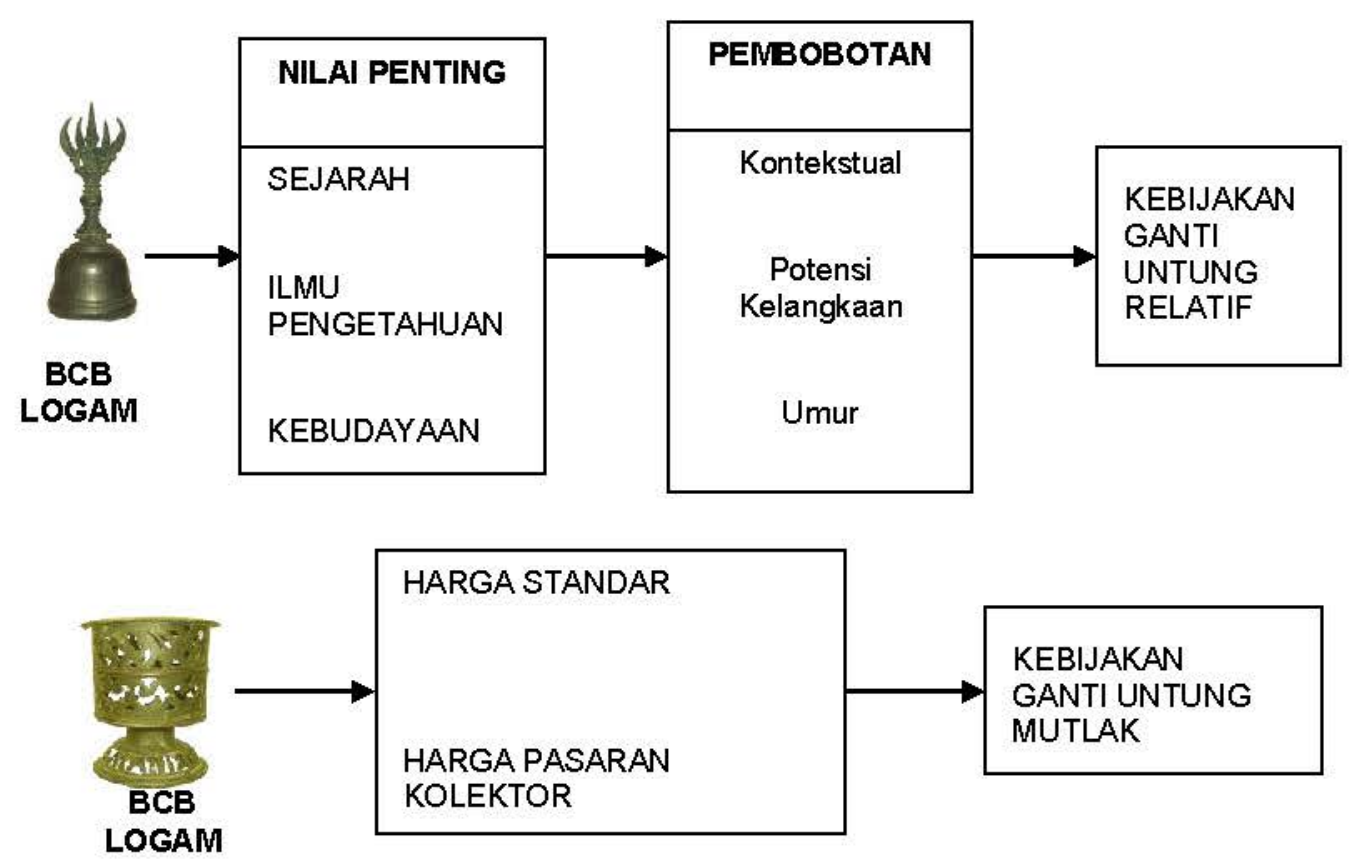

Dari skema berpikir yang telah disampaikan terdahulu, dapat diperoleh gambaran mengenai unsur - unsur yang dapat dipertimbangkan dalam memberikan imbalan untuk temuan benda cagar budaya logam.

Pertimbangan pertama, sudah pasti bahwa benda logam yang akan diberikan imbalan adalah benda cagar budaya yang mempunyai nilai penting bagi sejarah, ilmu pengetahuan, dan kebudayaan. Ketiga elemen nilai penting ini merupakan nilai makro yang perlu diberi bobot lebih khusus, agar dapat lebih mengarah ke pertimbangan penentuan kebijakan.

Unsur lebih kecil untuk pembobotan antara lain adalah Konteks, Potensi Kelangkaan, dan Umur. Ketiga bobot ini akan mengarahkan ke konsep kebijakan yang bersifat masih relatif. Adapun kebijakan yang bersifat mutlak (dengan penafsiran harga) dapat diperoleh dengan mengkombinasikan harga standard dengan harga pasaran yang beredar di antara para kolektor.

\section{KESIMPULAN}

Dari apa yang telah disampaikan sebelumnya ada beberapa kesimpulan yang dapat dicatat sebagai pertimbangan dalam penentuan imbalan untuk penemuan benda cagar budaya,

1. Benda cagar budaya yang akan diberikan imbalan harus benar - benar sudah dinilai dan mempunyai nilai penting sejarah, ilmu pengetahuan dan kebudayaan; 
2. Pembobotan dapat dilakukan dengan mengisi formulir yang memuat variabel - variabel kontekstual, potensi kelangkaan, dan umur;

3. Penafsiran harga benda cagar budaya logam dapat dipertimbangkan secara relatif maupun mutlak berdasarkan variabel - variabel yang ada, terutama dengan mempertimbangkan nilai harga intrinsik (bobot bahan dan harga jenis logam) serta harga pasaran (nilai jual nyata benda cagar budaya).

\section{KEPUSTAKAAN}

Departemen Pendidikan dan Kebudayaan. 1977. Himpunan Perundang undangan Republik Indonesia tentang Benda Cagar Budaya. Jakarta.

Michels, Joseph W. 1973. Dating Methods in Archeology. New York.

Pearson, M. P. dan S. Sullivan. 1995. Looking after heritage places. Melbourne: Melbourne University Press.

Renfrew, Colin dan Bahn, Paul. 1991. Archeology Theories Methods and Practise. London.

Sainth, George S. dan Ehrenhard, John E. 2002. "Protecting the Past to Benefit the Public". Dalam Public benefit of Archeology. University Press of Florida.

Sharer, Robert J. dan Ashmore, Wendy. 2003. Archeology Discovering our Past. New York.

Tanudirjo, Daud A. 2004. Penentuan Nilai Penting dalam Pengelolaan Benda Cagar Budaya. Jakarta.

Triharyantoro, Edi. 2000. "Potensi Kelangkaan Benda Cagar Budaya". Bulletin Cagar Budaya. Jakarta.

Van der Meulen S. J., W. J. 1987. IImu Sejarah dan Filsafat. Kanisius. Jakarta. 